\title{
Purification, characterization, and bioinformatics studies of phosphatidic acid phosphohydrolase from Lagenaria siceraria
}

\author{
Abul H. J. Ullah", Kandan Sethumadhavan, Casey Grimm, Jay Shockey \\ Southern Regional Research Center, ARS, USDA, New Orleans, USA \\ Email: ${ }^{*}$ abul.ullah@ars.usda.gov
}

Received 28 September 2012; revised 30 October 2012; accepted 8 November 2012

\begin{abstract}
Phosphatidic acid phosphohydrolase (PAP), EC 3.1.3.4, is the penultimate step in the Kennedy pathway of triacylglycerol (TAG) synthesis leading to the formation of diacylglycerol (DAG), which is a key intermediate in TAG synthesis. We partially purified a soluble PAP from mid maturing seeds of bottle gourd, Lagenaria siceraria. The steps include both anionic and cationic ion exchanger columns. Catalytic characterization of the partially purified PAP revealed that the optimum $\mathrm{pH}$ and temperature for activity were at $5.5^{\circ} \mathrm{C}$ and $45^{\circ} \mathrm{C}$. Under optimum assay condition using dioleoyl phosphatidic acid (DPA) as the substrate, the $V_{\text {max }}$ and $K_{m}$ were $0.36 \eta \mathrm{kat} / \mathrm{mg}$ of protein and $200 \mu \mathrm{M}$, respectively. For the synthetic sub$K_{m}$ were $33.0 \mathrm{nkat} / \mathrm{mg}$ of protein and $140 \mu \mathrm{M}$, respectively. The activity was neither inhibited nor enhanced by the presence of $\mathrm{Mg}^{2+}$ at a concentration range of 0 to $10 \mathrm{mM}$. Two major protein bands at 42-kDa and 27-kDa were visible in SDS-PAGE after partial purification. Bioinformatics analysis of trypsinized protein fractions containing PAP activity showed peptide sequences with sequence homology to various phosphate metabolizing enzymes including cucumber and castor bean purple acid phosphatase, polyphosphate kinase, fructose biphosphate aldolase, and enolase from various dicotyledonous plants including rice, corn, grape, and Arabidopsis lyrata.
\end{abstract}

Keywords: Phosphatidic Acid Phosphohydrolase; Lagenaria siceraria; Bioinformatics; TAG Biosynthesis

\section{INTRODUCTION}

Phosphatidic acid phosphohydrolase (PAP, 3-sn-phosphatidate phosphohydrolase, EC 3.1.3.4) hydrolyzes the phosphomonoester bond present in phosphatidate (PtdOH) yielding diacylglycerol (DAG) and $\mathrm{P}_{\mathrm{i}}$. Figure 1 sche-

*Corresponding author. matically describes the reaction catalyzed by PAP.

In the cytoplasmic membranes of plant seed tissue that accumulate storage triglycerides (TAG), fatty acyl groups are added sequentially by specific acyltransferase enzymes to the $s n-1, s n-2$, and $s n-3$ positions of glycerol-3-phosphate (G3P) to form TAG. This pathway was discovered in 1950s and commonly referred to as the Kennedy or G3P pathway [1]. A key step in the formation of TAG is the dephosphorylation of the $s n-3$ position of phosphatidic acid ( $\mathrm{PtdOH})$, which is formed by the action of two specific acyltransferases, namely, glycerol-3-phosphate acyltransferase (GPAT) and lysophosphatidic acid acyltransferase (LPAAT). The formation of DAG is therefore the penultimate step in Kennedy pathway. The DAG is not only crucial for de novo synthesis of TAG, but is also important for the synthesis of phosphatidylethanolamine (PtdEtn) and phosphatidylcholine (PtdCho) [2,3]. PAP is present not only in microbes and plants but also in animals; recent studies have shown that human lipin 1 is PAP [3]. The lipin 1 deficiency in mouse prevents normal adipose tissue development, which results in lypodystrophy, a disease marked by the loss of body fat and insulin resistance, conversely, overexpression of lipin 1 promotes obesity and insulin sensitivity [4-6]. The fact that lipin 1 is a PAP provides a scientific basis for how it regulates body fat metabolism in mam-

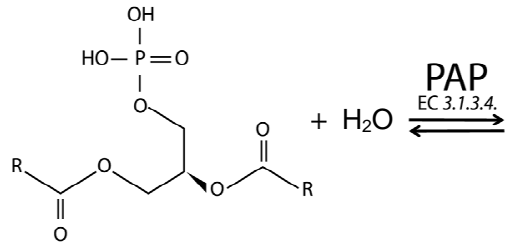

1,2- diacyglycerol 3-phosphate

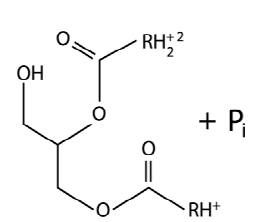

1,2- diacyglycerol
Figure 1. The schematic representation of enzymatic reaction catalyzed by phosphatidic acid phosphohydrolase (PAP). Phosphatidic acid $(\mathrm{PtdOH})$ yields DAG and $\mathrm{P}_{\mathrm{i}}$ when phosphoester linkage is hydrolyzed by PAP. 
malian cells. Therefore, PAP activity may represent a target of pharmaceutical research for the control of body fat synthesis in humans.

In the biosynthesis of TAG, PtdCho, and PtdEtn in developing seeds of oleaginous plants, the formation of DAG from PtdOH by the removal of inorganic orthophosphate $\left(\mathrm{P}_{\mathrm{i}}\right)$ from the latter is considered a crucial step [7]. Moreover, PAP has been reported as being a possible rate limiting step in TAG biosynthesis [8]. Therefore, if PAP does not function optimally, it could create a bottleneck in TAG, PtdCho, and PtdEtn biosynthesis. The kinetic and other physico-chemical data of this key biocatalyst from oleaginous plants is deemed useful for further study of plant fatty acid synthesis systems and for the development of novel and alternative oil sources. Such studies may provide insights into processes for further modification, enhancement, and control the total fatty acyl composition of TAG in oil-producing plants. Of particular interest to plant biochemists are the gene sequences that code for PAP, which may be useful for applications in genetic engineering of oleaginous crops to boost the oil content and at the same time in- corporate novel fatty acids in the seeds.

As an oleaginous crop, bottle gourd (L. siceraria) is an understudied plant whose kernel is about $50.3 \%$ (weight per weight) oil [9]. The mature kernels of L. siceraria contain four major triacylglycerols (TAGs) which include trilinolein (LLL), palmitoyldilinoleoyl glycerol (PLL), oleoyldilinoleoyl glycerol (OLL) and dioleoyllinoleoyl glycerol (OOL) [10]. L. siceraria PAP genes could play an important role in determining the fatty acid composition of seed TAG. In this study, we characterized L. siceraria PAP as detected in the crude supernatant derived from developing cotyledons by measuring activity, conducting kinetics experiments, and determining $\mathrm{pH}$ optima, temperature optima, and effects of minerals and other reagents of this key biocatalyst. This is the first documented reporting of PAP activity in $L$. siceraria .

\section{MATERIALS AND METHODS}

\subsection{Extraction of PAP from $L$. siceraria Cotyledons}

Asian bottle gourds belonging to Indian subcontinent and more specifically to Bengal region were grown in New Orleans and mid maturity level seeds were obtained from about 6 weeks old fruits. A $16.3 \mathrm{~g}$ of cotyledons were extracted from $107 \mathrm{~g}$ of seeds using a scalpel, washed in deionized water and then soaked in $30 \mathrm{ml}$ of extraction medium containing $25 \mathrm{mM}$ imidazole, $\mathrm{pH} 7.0,150 \mathrm{mM}$ sodium chloride, $5 \mathrm{mM}$ magnesium chloride, and 500 $\mu \mathrm{M}$ phenylmethylsulfonylfluoride (PMSF). The cotyledons were disrupted using a ground glass tissue homogenizer in an ice bath and then centrifuged at 18,000 $\times \mathrm{g}$ using Sorvall SS 34 rotor. The resulting pellet was discarded while the supernatant $(28 \mathrm{ml})$ was dialyzed overnight against $25 \mathrm{mM}$ imidazole, $\mathrm{pH} 7.0$ and $1 \mathrm{mM}$ magnesium chloride at $4{ }^{\circ} \mathrm{C}$ with three times buffer exchange. The dialyzed sample was centrifuged as before to remove the precipitated materials because the activity remained in the supernatant. The dialyzed supernatant after centrifugation still looked turbid; nonetheless, the material was applied to an ion-exchange column to facilitate purification of PAP.

\subsection{Purification of $L$. siceraria PAP}

Step 1. UNOsphere ${ }^{\mathrm{TM}} \mathbf{Q}$ anion exchange chromatography: A $35 \mathrm{ml}(2.5 \times 7.1 \mathrm{~cm})$ Kontes Flex-Column ${ }^{\circledR}$ was packed with hydrated UNOsphere ${ }^{\mathrm{TM}} \mathrm{Q}$ (Bio-Rad Laboratories, Inc. Hercules, CA) and equilibrated in 25 $\mathrm{mM}$ imidazole, $\mathrm{pH}$ 7.0, $1 \mathrm{mM}$ magnesium chloride buffer. A total of $177 \mathrm{mg}$ protein in $30 \mathrm{ml}$ imidazole buffer was applied to the column at a flow rate of $3.0 \mathrm{ml}$ per min using BioLogic LPTM chromatographic workstation at room temperature. The bound proteins were eluted using a series of discontinuous sodium chloride gradient at a 5\% interval starting from $5 \%$ to $30 \%$ and then at $10 \%$ interval from $30 \%$ to $50 \%$. Finally, the column was washed with $100 \%$ sodium chloride in imidazole buffer. An automated fraction collector was used holding the fraction size to $6.0 \mathrm{ml}$. Fractions were assayed for PAP activity using dioleoyl phosphatidic acid and general purpose acid phosphatase activity using $\rho$-nitrophenylphosphate ( $\rho \mathrm{NPP})$.

Step 2. UNOsphere ${ }^{\mathrm{TM}} \mathrm{S}$ cation exchange chromatography: The active fractions from the previous step (fractions 15 through 23) were pooled and dialyzed against $50 \mathrm{mM}$ sodium acetate, $\mathrm{pH} 5.0$, and $1 \mathrm{mM}$ magnesium chloride and loaded onto a $5 \mathrm{ml} \mathrm{S}$ column $(1.5 \times$ $2.8 \mathrm{~cm})$ Kontes Flex-Column ${ }^{\circledR}$ at the flow rate of $1.0 \mathrm{ml}$ per min. The bound proteins were eluted using a series of discontinuous sodium chloride gradients in acetate buffer at the same flow rate at a 5\% interval starting from $5 \%$ to $30 \%$ and then at $10 \%$ interval from $30 \%$ to $50 \%$ sodium chloride. Finally, the column was eluted with $100 \%$ sodium chloride in acetate buffer. The column eluate was fractionated for $5 \mathrm{~min}$ each at the flow rate of $1.0 \mathrm{ml}$ per min and assayed for both PAP and $\rho$ NPP-based acid phosphatase activity.

Step 3. UNOsphere ${ }^{\mathrm{TM}} Q$ cation exchange chromatography: The active fractions from the previous step (fractions 26 through 31) totaling $30 \mathrm{ml}$ were pooled and dialyzed against $25 \mathrm{mM}$ imidazole, $\mathrm{pH} 7.4$ buffer supplemented with $1 \mathrm{mM}$ magnesium chloride and loaded onto a $1.0 \mathrm{ml}$ cartridge column pre-packed with $\mathrm{Q}$ cation exchange resin, which was equilibrated in the same buffer at the flow rate of $1.0 \mathrm{ml}$ per min. The bound proteins were eluted using a series of discontinuous sodium chloride 
gradients in imidazole buffer at the same flow rate at a 5\% interval starting from $5 \%$ to $30 \%$ and then at $10 \%$ interval from $30 \%$ to $50 \%$ sodium chloride. Finally, the column was eluted with $100 \%$ sodium chloride in imidazole buffer. The column eluate was fractionated for $5 \mathrm{~min}$ each and assayed for both PAP and acid phosphatase activity.

\subsection{Gel Electrophoresis}

Electrophoresis of the purified PAP enzyme was performed using Xcell II, Mini-Cell and 4\% - 12\% Novex ${ }^{\mathrm{TM}}$ NuPage Bis-Tris gels with MOPS as running buffer. (Life Technologies, Grand Island, NY). Successful separation was achieved at a constant $200 \mathrm{~V}$ and 70 min run. For gel calibration, prestained and multicolored molecular weight markers (4 to $250-\mathrm{kDa}$ ) were used as standards. The separated protein bands were visualized with Pierce (Thermoscientific, Rockford, IL) silver staining kit.

\subsection{Measurement of Inorganic Orthophosphate $\left(P_{i}\right)$ Released by PAP}

To measure nmole level of $\mathrm{P}_{\mathrm{i}}$ released by L. siceraria PAP from the substrate, dioleoyl phosphatidic acid (1,2dioleoyl-sn-glycero-3-phosphate, sodium salt, Avanti polar lipids, Inc.), we used ammonium molybdate-based acetone-molybdate-acid (AMA) method [11]. The reaction volume was fixed at $1.0 \mathrm{~mL}$ to which was added 50 $\mathrm{mM}$ sodium acetate, $\mathrm{pH} 5.5,25$ to $50 \mu \mathrm{L}$ of samples containing $L$. siceraria PAP enzyme followed by $50 \mu \mathrm{L}$ of $10 \mathrm{mM}$ dioleoyl phosphatidic acid to start the enzymatic reaction. Experiments were conducted in a $45^{\circ} \mathrm{C}$ water bath for up to $30 \mathrm{~min}$. To stop the reaction $2 \mathrm{~mL}$ freshly prepared AMA reagent was added. After $30 \mathrm{sec}$, $0.1 \mathrm{~mL}$ of citric acid $(1.0 \mathrm{M})$ was added to each tube to fix the color. To remove turbidity we centrifuged the reaction mix in an Eppendorf 5415C at 13,000 $\times \mathrm{g}$ for 7 min. The clarified reaction mix was read at $355 \mathrm{~nm}$ after blanking the spectrophotometer with the appropriate control run at zero time. PAP activity was expressed as $\mathrm{nkat} / \mathrm{ml}$ (nmoles ortho-phosphate liberated per sec).

\subsection{Acid Phosphatase Activity Measurement}

A 5 to $20 \mu \mathrm{L}$ of PAP enzyme samples were incubated in $50 \mathrm{mM}$ acetate buffer, $\mathrm{pH} 5.5$ with 1.25 mmoles of $\rho$-nitrophenylphosphate ( $\rho \mathrm{NPP})$ in a final volume of 1.0 $\mathrm{mL}$ at $45^{\circ} \mathrm{C}$ for 1 to $2 \mathrm{~min}$. The reaction was terminated adding $0.1 \mathrm{~mL} 1.0 \mathrm{~N}$ sodium hydroxide to the reaction mix and the liberated $\rho$-nitrophenol was measured spectrophotometrically at $400 \mathrm{~nm}$ [12].

\subsection{Tryptic Digestion of the Purified PAP Enzyme}

A $200 \mu \mathrm{L}$ of the enzyme from UNOsphere ${ }^{\mathrm{TM}} \mathrm{Q}$ column (step 4) was concentrated in a Centricon-10 ${ }^{\mathrm{TM}}$ (Amicon $^{\mathrm{TM}}$ centrifugal filter devices, Millipore Corporation, Billerica, MA) concentrator and in the process the buffer was exchanged to protease digestion buffer $(50 \mathrm{mM}$ ammonium carbonate, $\mathrm{pH} 8.0$ ). The protein concentration of this preparation was $11 \mathrm{mg} / \mathrm{mL}$.

The tryptic digests were prepared using Thermo Scientific in-solution tryptic digestion and guanidination kit. Briefly, 5 to $10 \mu \mathrm{g}$ of protein was added to $15 \mu \mathrm{L}$ digestion buffer containing $5.6 \mathrm{mM}$ DTT in a total volume of $27 \mu \mathrm{L}$. The mixture placed in a microcentrifuge tube was incubated at $95^{\circ} \mathrm{C}$ for $5 \mathrm{~min}$. To alkylate the proteins, 3 $\mu \mathrm{L}$ of $100 \mathrm{mM}$ iodoacetamide was added and kept in the dark at room temperature. A $2 \mu \mathrm{L}$ aliquot of activated trypsin $(100 \eta \mathrm{g} / \mu \mathrm{L})$ was added to each tube and incubated at $37^{\circ} \mathrm{C}$ for $3 \mathrm{hr}$. To achieve complete digestion the incubation was continued further for $2 \mathrm{hr}$ after the addition of $1 \mu \mathrm{L}$ of trypsin. The digests were guanidilated to convert lysine to homoarginine by mixing the contents with $10 \mu \mathrm{L}$ of $30 \%$ ammonium hydroxide and $6 \mu \mathrm{l}$ of guanidination reagent $(50 \mathrm{mg} \mathrm{O}$-methylisourea hemisulfate in $51 \mu \mathrm{L}$ ultrapure water) and incubated at $65^{\circ} \mathrm{C}$ for $12 \mathrm{~min}$. The reaction was stopped by the addition of $3 \mu \mathrm{L}$ of trifluoro acetic acid (TFA) and stored at $-20^{\circ} \mathrm{C}$ before sequence analysis.

\subsection{Peptide Separation, Sequencing and Similarity Search for Bioinformatics Studies}

The tryptic digests from the active step 4 (Table 1) Lagenaria siceraria PAP were analyzed via LC/MS/MS, using an Agilent 1200 LC system, an Agilent Chip-cube interface, and an Agilent 6520 Q-TOF tandem mass spectrometer (Agilent Technologies, Santa Clara, CA). Chromatographic separation of the peptides was accomplished using a Chip consisting of a $40 \mathrm{~nL}$ enrichment column and a $43 \mathrm{~mm}$ analytical column packed with $\mathrm{C} 18$, $5 \mu \mathrm{m}$ beads with $300 \AA$ pores. One $\mu \mathrm{L}$ aliquots of the sample were transferred to the enrichment column via a capillary pump operating at a flow of $4 \mu \mathrm{L} / \mathrm{min}$. The nano pump was operated at a flow rate of $600 \mathrm{~nL} / \mathrm{min}$. An initial gradient (Solvent A: 100\% water, 0.1\% formic acid; Solvent B: 90\% acetonitrile (ACN), 10\% water and $0.1 \%$ formic acid) of $97 \%$ A was changed to $60 \%$ Solvent A at $12 \mathrm{~min}, 20 \%$ at $13 \mathrm{~min}$, and held till $15 \mathrm{~min}$. A post run time of $3 \mathrm{~min}$ was employed for column equilibration.

The MS source was operated at $300^{\circ} \mathrm{C}$ with $5 \mathrm{~L} / \mathrm{min}$ $\mathrm{N}_{2}$ flow and a fragmentor voltage of $175 \mathrm{~V} . \mathrm{N}_{2}$ was used as the collision gas with collision energy varied as a function of mass and charge using a slope of $3.7 \mathrm{~V} / 100$ $\mathrm{Da}$ and an offset of $2.5 \mathrm{~V}$. Both quad and Time-of-Flight (TOF) were operated in positive ion mode. Reference compounds of 322.048121 Da and 1221.990637 Da were continually leaked into the source for mass calibration. 
An initial MS scan was performed from m/z 300 to 1600 and up to three multiply charged ions were automatically selected for MS/MS analysis. Following the initial run, a second injection was made excluding ions previously targeted for MS/MS analysis. LC chromatograms and mass spectra were examined using Mass-Hunter software (Version B.0301; Agilent Technologies, Santa Clara, CA). Data files were transferred to an Agilent workstation equipped with Spectrum Mill software (Agilent Technologies, Santa Clara, CA). The raw MS/MS data files were extracted, sequenced, and searched against the $\mathrm{Na}-$ tional Center for Biotechnology Information (NCBI) non redundant protein library.

\section{RESEULTS}

\subsection{Purification}

We employed a regimen of both anion and cation exchange chromatography to purify L. siceraria PAP from developing cotyledons. The results are shown in Table 1. Judging from the binding of PAP to both anion and cation exchange column at $\mathrm{pH} 7.0$ and $\mathrm{pH} 5.0$ respectively, we conclude that the isoelectric point of the biocatalyst lies closer to $\mathrm{pH} 7.0$ than $\mathrm{pH} 5.0$.

It is worth noting here that the flow through of Q column had turbidity and very little PAP activity associated with it. This also indicates that microsomal fraction of the preparation had a negligible PAP activity. This bolsters our notion that we have identified a soluble PAP activity in the cotyledon extract of Lagenaria siceraria. Figure 2 (panel A) shows the elution profile of first Q column where 6 protein peaks were visible. These were eluted by discontinuous salt gradient starting from 50 $\mathrm{mM}$ through $300 \mathrm{mM}$ salt concentration. The first peak, which was eluted with $5 \%$ salt had PAP activity, whereas, the second and third peak showed both PAP and $\rho$ NPP activity. Only the first peak was pooled, dialyzed, and applied to the second ion exchange S column. The PAP activity which bound to the cation exchange column at pH 5.0 was eluted at $300 \mathrm{mM}$ and $400 \mathrm{mM}$ salt concentration (Figure 2 panel B). The PAP activity was bound to the third ion exchange column and eluted with 100 $\mathrm{mM}$ sodium chloride in imidazole buffer (Figure 2 panel
C). Of the three protein peaks eluted in the last column all the PAP activity was associated with the second protein peak.

The partially purified PAP from the third ion exchange column (UNOsphere ${ }^{\mathrm{TM}} \mathrm{Q}$ ) was visualized by SDS-PAGE and shown in Figure 3. Two major protein bands one at $42-\mathrm{kDa}$ and the other at $27-\mathrm{kDa}$ were observed. These two protein bands are tentative candidates for $L$. siceraria PAP. There were however several minor contaminating protein bands which co-purified with PAP.

There was a rapid loss of enzymatic activity as the preparation underwent ion exchange chromatography. By the time the second UNOsphere ${ }^{\mathrm{TM}} \mathrm{Q}$ column was completed, the purified preparation had lost $99 \%$ of the PAP activity (Table 1). Thus, no further purification was attempted.

\subsection{Biochemical Characterization of $L$. siceraria PAP}

To characterize the catalytic properties of $L$. siceraria PAP, we used the active preparations from the third step of purification (Table 1), which is the $\mathrm{S}$ cation exchange column, because the activity dropped precipitously in the next step of purification, i.e., the second $\mathrm{Q}$ anion exchange column. To establish the rate linearity of the enzyme reaction we added increasing amounts of enzyme while holding dioleoyl phosphatidic acid concentration $(500 \mu \mathrm{M})$ and the time of incubation $(60 \mathrm{~min})$ fixed. The inorganic orthophosphate liberated by PAP are shown in Figure 4. The catalytic rate was shown to increase linearly as a function of enzyme concentration (6 to $30 \mu \mathrm{g}$ of protein per $\mathrm{ml}$ ) when assayed at $45^{\circ} \mathrm{C}$ in sodium acetate buffer at $\mathrm{pH}$ 5.5.

The $\mathrm{pH}$ and temperature optima were empirically determined to be $5.5^{\circ} \mathrm{C}$ and $45^{\circ} \mathrm{C}$, respectively (Table 2). Performing the enzyme assay at $45^{\circ} \mathrm{C}$ and $\mathrm{pH} 5.5$ while using dioleoyl phosphatidic acid as the substrate we calculated the $\mathrm{V}_{\max }$ and $\mathrm{K}_{\mathrm{m}}$ to be 0.36 ikat per $\mathrm{mg}$ and 200 $\mu \mathrm{M}$, respectively. When the same protein sample was used to determine the kinetic parameters of L. siceraria PAP for the synthetic acid phosphatase substrate, $\rho$ NPP,

Table 1. Purification of Lagenaria siceraria phosphatidic acid phosphohydrolase from developing cotyledon.

\begin{tabular}{|c|c|c|c|c|c|c|}
\hline Step & Volume & Total activity $^{*}$ & Total protein & Specific activity & Purification (fold) & Yield (\%) \\
\hline & $(\mathrm{mL})$ & ( $\eta$ kat) & (mg) & (nkat/mg) & & \\
\hline 1) Crude extract & 30 & 106.0 & 177.0 & 0.59 & 1.0 & 100.0 \\
\hline 2) UNOsphere Q column & 50 & 36.0 & 33.0 & 1.10 & 1.9 & 18.6 \\
\hline 3) UNOsphere S column & 30 & 11.2 & 3.5 & 3.20 & 5.4 & 10.6 \\
\hline 4) UNOsphere Q column & 20 & 1.1 & 1.3 & 0.84 & 1.4 & 0.6 \\
\hline
\end{tabular}

*PAP activity determined using dioleoyl phosphatidic acid as the substrate. 

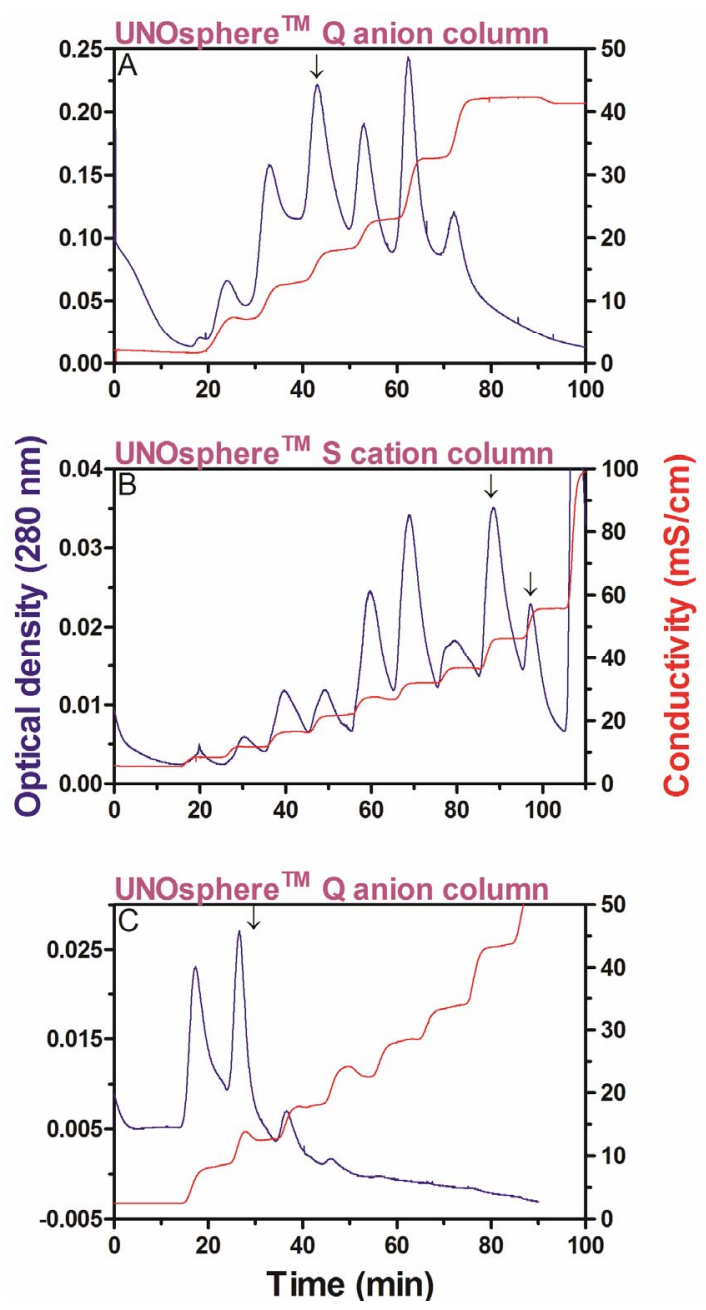

Figure 2. Chromatographic elution profile of developing cotyledon proteins from $L$. siceraria as generated by UNOsphere ${ }^{\mathrm{TM}} \mathrm{Q}$ (Panel A), UNOsphere ${ }^{\mathrm{TM}} \mathrm{S}$ (Panel B), and UNOsphere ${ }^{\mathrm{TM}} \mathrm{Q}$ columns (Panel C). The solid line represents $\mathrm{A}_{280}$ and the dotted line represents conductivity $(\mathrm{mS} / \mathrm{cm})$. See methods section for details of ion-exchange chromatographies. The arrow shows the position where the PAP activity was eluted in the discontinuous salt gradient.

the $V_{\max }$ and $\mathrm{K}_{\mathrm{m}}$ was found to be 33 nkat per mg and 140 $\mu \mathrm{M}$ (Table 2).

We also have explored the role of $\mathrm{Mg}^{2+}$ in L. siceraria PAPactivity. Enzyme activity was unaffected by magnesium concentrations from $0-10 \mathrm{mM}$.

\subsection{Bioinformatics with $L$. siceraria PAP}

Against the backdrop of declining PAP activity after step 4 (UNOsphere ${ }^{\mathrm{TM}} \mathrm{Q}$ anion exchange column) of the purification regimen (Table 1), the active fractions were pooled and tryptic digestion of the pooled protein performed to aid in sequencing peptides potentially emanating from highly purified PAP. We expected some de-

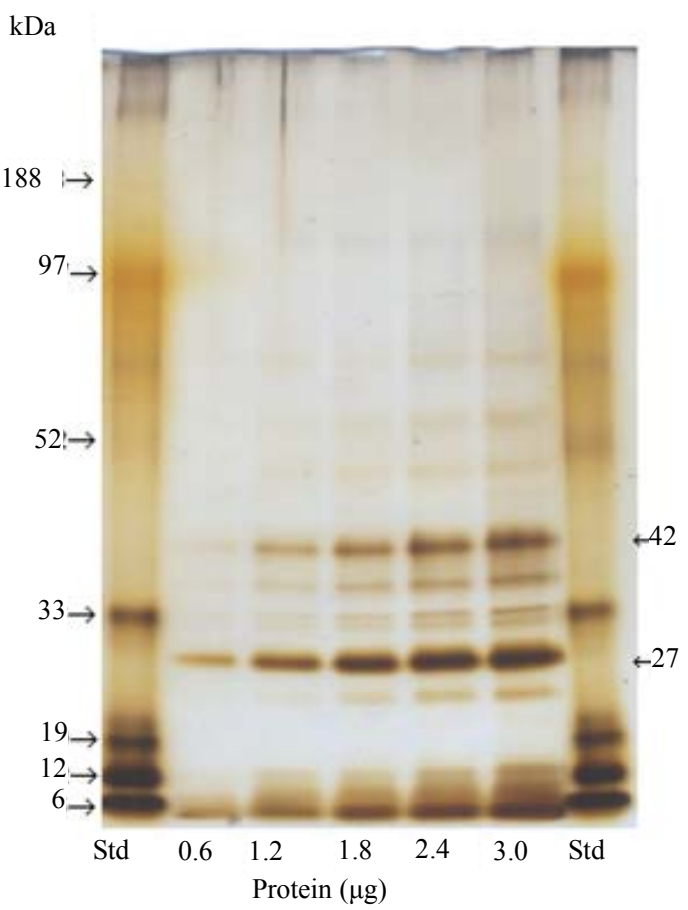

Figure 3. SDS-PAGE profile of silver-stained proteins from step 3 purified $L$. siceraria cotyledon PAP derived from the second $\mathrm{A}_{280}$ peak (marked by arrow) of Figure 2 panel C. The gel was loaded with increasing amounts of proteins ( 0.6 to $3 \mu \mathrm{g}$ per lane) to visualize the contaminating proteins.

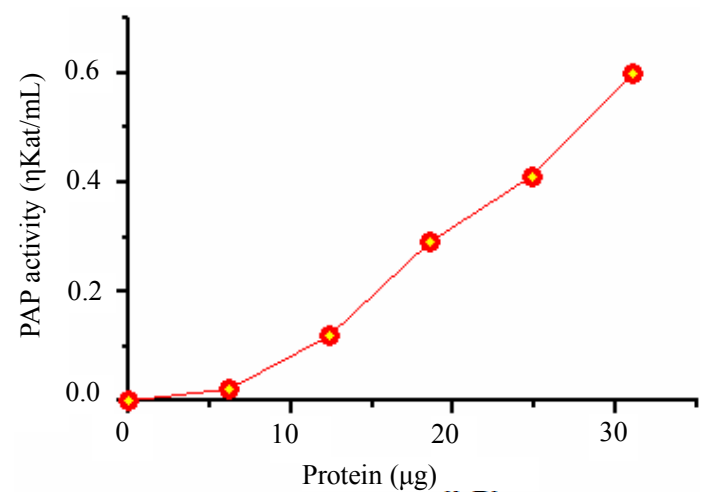

Figure 4. The rate linearity of in vitro L. siceraria PAP activity as a function of protein concentration.

Table 2. Kinetic properties of $L$. siceraria PAP.

\begin{tabular}{ll}
\hline Parameters & Values \\
\hline $\mathrm{pH}$ optimum & 5.5 \\
Temperature optimum & $45^{\circ} \mathrm{C}$ \\
$\mathrm{V}_{\max }$ for dioleoyl phosphatidic acid & $0.36 \eta \mathrm{kat}$ per $\mathrm{mg}$ \\
$\mathrm{K}_{\mathrm{m}}$ for dioleoyl phosphatidic acid & $200 \mu \mathrm{M}$ \\
$\mathrm{V}_{\max }$ for $\rho$-nitrophenylphosphate & $33 \eta \mathrm{kat}$ per $\mathrm{mg}$ \\
$\mathrm{K}_{\mathrm{m}}$ for $\rho$-nitrophenylphosphate & $140 \mu \mathrm{M}$ \\
\hline
\end{tabular}


gree of contamination from non-PAP candidate peptides but sought to identify possible PAP sequences by performing sequence similarity searches against available plant sequence databases. Therefore, the peptides from GC-Mass Spectroscopy were searched against the NCBI non redundant protein library. Altogether there were about 128 proteins that showed varying degrees of identity to the trypsinized seed extract peptides. Our sample contained multiple peptides that matched with $13 \%-16 \%$ of the total sequence of methionine synthase (EC 2.1.1.13) from a diversified group of plants such as potato, grape, castor bean, soybean, beet, Arabidopsis lyrata, etc., and $14 \%$ sequence identity to glutamate dehydrogenase (EC 1.4.1.2) of castor oil plant.

A few peptides from PAP tryptic digest however showed sequence homology to a diversified groups of phosphate metabolism enzymes such as enolase or phosphopyruvate hydratase (EC 4.2.1.11), fructose-biphosphate aldolase (EC 4.1.2.13), gamma-glutamyltransferase (EC 2.3.2.2), hydrogen dehydrogenase (EC 1.12.1.3), PEP-dependent phosphotransferase system (EC 2.7.3.9), and polyphosphate kinase (2.7.4.1). These L. siceraria peptides are listed in Table 3. Also noteworthy are $L$. siceraria peptide sequences similar to purple acid phosphatase (EC 3.1.3.2).

\section{DISCUSSION}

L. siceraria or bottle gourd is a dual-purpose crop both used as vegetables and folk medicine in India [13-15]. The oil content of the mature seeds is very high; as such, L. siceraria and other cucurbits could serve as model systems for understanding the metabolic pathway of triacylglycerol (TAG) formation in plant seeds. Furthermore, multiple genetic resources for cucurbit genomics are now available

(http://www.icugi.org/cgi-bin/ICuGI/misc/project.cgi), which will make the task of locating the genes for Kennedy pathway enzymes less arduous.

Phosphatidic acid phosphohydrolase (PAP) is considered to be a key enzyme in the regulation of lipid synthesis [16]. This key biocatalyst has not been identified in oleaginous cucurbits. Ours is an attempt to identify and characterize the seed PAP from L. siceraria, an important member of the cucurbitaceae family.

We were able to follow the PAP activity in a purification regimen that employed both anion and cation exchange chromatography. However, the activity declined rapidly after the second Q anion exchange column (Step 4). One possibility merits mentioning here, which is the milieu in which TAG is synthesized. The conditions used for binding and elution of the PAP from the ion exchange column may have separated a required co-factor or subjected the biocatalyst to misfolding or distortion of the active site or substrate-binding domain.

The biochemistry, subcellular targeting, and putative physiological roles of PAP are complex and not yet completely understood. PAP activities are found in both the

Table 3. Peptides from proteins purified from L. siceraria seed that showed sequence homology to various phosphate metabolism enzymes.

\begin{tabular}{|c|c|c|}
\hline Peptides obtained from L. siceraria cotyledons & Identity & $\begin{array}{l}\text { Accession } \\
\text { number }\end{array}$ \\
\hline 1) KFGIIGDLGQTFNSLSTLKH & Purple acid phosphatase (EC 3.1.3.2) from Cucumis sativus & A1BQL4 \\
\hline 2) KSAPVYITVGDGGNQEGLAGRF & Purple acid phosphatase (EC 3.1.3.2) from Ricinus communis & B9RP16 \\
\hline 3) KTAARDPFVVAIKQ & Polyphosphate kinase (EC 2.7.4.1) from Thiomonas intermedia & D5X1T9 \\
\hline 4) RGNPTVEVDVILSDGTLARA & Enolase (EC 4.2.1.11) from Ricinus communis & B9R9N6 \\
\hline 5) KSFASEYPIVSIEDPFDQDDWEHYSKL & Enolase (EC 4.2.1.11) from Ricinus communis & B9R9N6 \\
\hline 6) KVNQIGSVTESIEAVKM & Enolase (EC 4.2.1.11) from Oryza sativa & A1YQJ3 \\
\hline 7) RSGETEDTFIADLSVGLATGQIKT & Enolase (EC 4.2.1.11) from Gossypium hirsutum & A8IMP0 \\
\hline 8) RALQQSTIKK & Fructose-biphosphate aldolase (EC 4.1.2.13) from Oryza sativa & B8B4J4 \\
\hline 9) RLASINVENVESNRRA & Fructose-biphosphate aldolase (EC 4.1.2.13) from Arabidopsis lyrata & D7LJ40 \\
\hline 10) KEGGVLPGIKV & Fructose-biphosphate aldolase (EC 4.1.2.13) from Vitis vinifera & A5B118 \\
\hline 11) RTVPAAVPAVVFLSGGQSEEEATLNLNAMNKL & Fructose-biphosphate aldolase (EC 4.1.2.13) from Zea mays & B4FWP0 \\
\hline 12) KVAPEVVAEYTVRA & Fructose-biphosphate aldolase (EC 4.1.2.13) from Ricinus communis & B9SRH4 \\
\hline 13) KCAEVTERV & Fructose-biphosphate aldolase (EC 4.1.2.13) from Physcomitrella patens & A9S0F9 \\
\hline 14) KYYEAGARF & Fructose-biphosphate aldolase (EC 4.1.2.13) from Toxoplasma gondii & B6KMB6 \\
\hline 15) RFVLKDQTQVDYPRL & Phosphotransferase system EIIC (EC 2.7.3.9) from Pantoea sp & E0LSS4 \\
\hline
\end{tabular}


cytosolic and membrane fractions of yeast $[6,17]$ and plants [18-21]. Type II PAPs are $\mathrm{Mg}^{2+}$-independent integral membrane proteins. Type I PAPs are $\mathrm{Mg}^{2+}$-dependent and are often found distributed between cytosolic and membrane fractions. Type II PAPs seem to play no role in bulk cellular lipid metabolism, but are likely involved in signal transduction pathways [17,22,23]. Type I enzymes on the other hand, have been implicated in a direct role in phospholipid and triacylglycerol synthesis in yeast [6] and phospholipid and galactolipid synthesis in plants [18-20]. Ample evidence from yeast, plant, and mammalian systems suggests that type I PAP acts as both a metabolic enzyme and a transcriptional regulator [20, $24,25]$. In yeast, both roles appear to rely on phosphatidic acid phosphohydrolase enzymatic activity, as mutations of critical catalytic residues render the enzyme unable to complement various mutant phenotypes [26].

The PAP characterized in this report most closely resembles the properties described by Pearce et al. [17] who partially purified a PAP activity from Persea americana (avocado) fruit. The enzyme was shown to be about 49-kDa by SDS-PAGE analysis. This protein was peripherally associated with the microsomal fraction, and could be dissociated from membranes using high salt and partially purified through the use of surfactants. The avocado enzyme did not require $\mathrm{Mg}^{2+}$ for activity, but was slightly stimulated by addition of $1 \mathrm{mM} \mathrm{MgCl}_{2}$ [17]. The L. siceraria PAP preparation reported in this communication is unique in that it was found to be cytosolic and completely insensitive to magnesium. This is the first time that such a PAP was reported, and as such, the protein present in our preparations may represent a new class of PAP enzyme.

Unfortunately, neither the peptide nor gene sequence corresponding to the $49-\mathrm{kDa}$ avocado protein has been reported; therefore, we cannot compare it to any of our peptide sequences.

However, the sequence similarity search with peptides generated from partially purified $L$. siceraria PAP has provided a plethora of information. Clearly, some of the peptides generated from the active fractions of the last UNOsphere ${ }^{\mathrm{TM}} \mathrm{Q}$ column were not engendered from PAP; however, a significant number of peptides showed homology to phosphate metabolizing enzymes such as polyphosphate kinase (EC 2.7.4.1), enolase or 2-phosphoglyceratedehydratase (EC 4.2.1.11), fructose-biphosphate aldolase (EC 4.1.2.13), and purple acid phosphatase (EC 3.1.3.2) (Table 3). It is coincidental that both phosphatidic acid phosphohydrolase and purple acid phosphatase hydrolyze phosphomonoester bonds and it is possible that their catalytic sites may be structurally similar. However, we expect the substrate-binding domain to be markedly different in these two phosphomonoesterases. When the Momordica charantia seed transcip- tome was analyzed for conjugated fatty acid metabolism-related genes, the 50 most abundant transcript reads in the non-normalized cDNA library contained enolase [27]. We also noticed several peptides in purified $L$. siceraria PAP that showed homology to enolase from castor bean, rice, and cotton (Table 3).

Literature is not replete with PAP from cucurbits; therefore, enzymatic characterization and sequence information of this important biocatalyst of lipid synthesis may stimulate further research in oleaginous plants belonging to the family Cucurbitaceae. To our knowledge this is the first documented reporting of any PAP from cucurbitaceae. The bioinformatics studies of PAP and other co-purified proteins from L. siceraria developing seeds have shown sequence similarities with a few phosphate metabolizing enzymes including purple acid phosphatase. It has not escaped our attention that phosphatidic acid phosphohydrolase or PAP (EC 3.1.3.4) is also capable of degrading $\rho$-nitrophenylphosphate, which is a general purpose acid phosphatase. Therefore, the PAP may share sequence homology with purple acid phosphatase. The final confirmation will come from cloning PAP genes from other well-studied oleaginous plants such as Momordica charantia and Vernicia fordii and overexpression in heterologous host such as Pichia pastoris. Now that cucurbit genome sequences are becoming available

(http://www.icugi.org/cgi-bin/ICuGI/misc/project.cgi), the bioinformatics work vis-à-vis phosphatidic acid phosphohydrolase may yield a plethora of information regarding the conservation of PAP types between $L$. siceraria PAP and the Cucurbitaceae family, and higher plants in general.

\section{REFERENCES}

[1] Smith, S.W., Weiss, S.B. and Kennedy, E.P. (1957) The enzymatic dephosphorylation of phosphatidic acid. Journal of Biological Chemistry, 228, 915-922.

[2] Kennedy, E.P. and Weiss, S.B. (1956) The function of cytidine coenzyme in the biosynthesis of phospholipids. Journal of Biological Chemistry, 222, 193-214.

[3] Kocsis, M.G. and Weselake, R.J. (1996) Phosphatidate phosphatases of mammals, yeast, and higher plants. Lipids, 31, 785-802. doi:10.1007/BF02522974

[4] Peterfy, M., Phan, J, Xu, P. and Reue, K. (2001) Lipodystrophy in the fld mouse results from mutation of a new gene encoding a nuclear protein, lipin. Nature Genetics, 27, 121-124. doi:10.1038/83685.

[5] Phan, J. and Reue, K. (2005) Lipin, a lypodystrophy and obesity gene. Cell Metabolism, 1, 73-83. doi:10.1016/j.cmet.2004.12.002

[6] Han, G.S., Wu, W.I. and Carman, G.M. (2006) The Saccharomyces cerevisiae lipin homolog is a $\mathrm{Mg}^{2+}$-dependent phosphatidate phosphatase enzyme. The Journal of 
Biological Chemistry, 281, 9210-9218. doi:10.1074/jbc.M600425200

[7] Kennedy, E.P. (1961) Biosynthesis of complex lipids. Federation Proceedings, 20, 934-940.

[8] Stymne, S. and Stobart, A.K. (1987) Triacylglycerol biosynthesis. In: Stumpf, P.K. and Conn, E.E., Eds., The Biochemistry of Plants, Academic Press, Orlando, 175214.

[9] Loukou, A.L., Lognay, G., Barthelemy, J.P., Maesen, P., Baudoin, J.P. and Zoro, B.I. (2011) Effect of harvest time on seed oil and protein contents and compositions in the oleaginous gourd Lagenaria siceraria (Molina) Standl. Journal of the Science of Food and Agriculture, 91, 20732080. doi:10.1002/jsfa.4422

[10] Akintayo, C.O., Akintayo, E.T., Akinsola, A. and Ziegler, T. (2009) Matrix-Assisted Laser Desorption Ionization time of flight mass spectrometric analysis of some curcurbita oils for triacylglycerol composition. Rivista Italiana Delle Sostanze Grasse, 86, 237-241.

[11] Heinonen, J.K. and Lahti, R.J. (1981) A new and convenient calorimetric determination of inorganic orthophosphate and its application to the assay of inorganic pyrophosphates. Analytical Biochemistry, 113, 313-317. doi:10.1016/0003-2697(81)90082-8

[12] Ullah, A.H.J. and Cummins, B.J. (1987) Purification, Nterminal amino acid sequence and characterization of $\mathrm{pH}$ 2.5 optimum acid phosphatase (E.C. 3.1.3.2) from Aspergillus ficuum. Preparative Biochemistry, 17, 397-422. doi: $10.1080 / 00327488708062504$

[13] Akhtar, M.S., Iqbal, Z., Khan, M.N. and Lateef, M. (2000) Anthelmintic activity of medicinal plants with particular reference to their use in animals in the Indo-Pakistan subcontinent. Small Ruminant Research, 38, 99-107. doi:10.1016/S0921-4488(00)00163-2

[14] Badifu, G. (1991) Chemical and physical analyses of oils from 4 species of cucurbitaceae. Journal of the American Oil Chemists Society, 68, 428-432. doi:10.1007/BF02663761

[15] Tsieri, M.M., Niamayoua, R.K., Mampouya, D., Silou, T., Trémolières, A., Héron, S. and Tchapla, A. (2008) Comparative study of fatty acids and triglycerids of Luffa cylindrica versus cucurbitaceae seeds consumed in Congo Brazzaville. Pakistan Journal of Nutrition, 7, 733-740.

[16] Pearce, M.L. and Slabas, A.R. (1998) Phosphatidate phosphatase from avocado (Persea americana)-Purification, substrate specificity and possible metabolic implications for the Kennedy pathway and cell signaling in plants. The Plant Journal, 14, 555-564. doi:10.1046/j.1365-313X.1998.00152.x

[17] Faulkner, A.J., Chen, X., Rush, J., Horazdovsky, B., Waechter, C.J., Carman, G.M. and Sternweis, P.C. (1999) The LPP1 and DPP1 gene products account for most of the isoprenoid phosphate phosphatase activities in Saccharomyces cerevisiae. The Journal of Biological Chemistry, 274, 14831-14837. doi:10.1074/jbc.274.21.14831
[18] Eastmond, P.J., Quettier, A.L., Kroon, J.T., Craddock, C., Adams, N. and Slabas, A.R. (2010) Phosphatidic acid phosphohydrolase 1 and 2 regulate phospholipid synthesis at the endoplasmic reticulum in Arabidopsis. Plant Cell, 22, 2796-2811. doi:10.1105/tpc.109.071423

[19] Nakamura, Y., Koizumi, R., Shui, G., Shimojima, M., Wenk, M.R., Ito, T. and Ohta, H. (2009) Arabidopsis lipins mediate eukaryotic pathway of lipid metabolism and cope critically with phosphate starvation. Proceedings of the National Academy of Sciences of the United States of America, 106, 20978-20983. doi:10.1073/pnas.0907173106

[20] Mietkiewska, E., Siloto, R.M.P., Dewald. J., Shah, S., Brindley, D.N. and Weselake, R.J. (2011) Lipins from plants are phosphatidate phosphatases that restore lipid synthesis in a pah1D mutant strain of Saccharomyces cerevisiae. FEBS Journal, 278, 764-775. doi:10.1111/j.1742-4658.2010.07995.x

[21] Pierrugues, O., Brutesco, C., Oshiro, J., Gouy, M., Deveaux, Y., Carman, G.M., Thuriaux, P. and Kazmaier, M. (2001) Lipid phosphate phosphatases in Arabidopsis. Regulation of the AtLPP1 gene in response to stress. The Journal of Biological Chemistry, 276, 20300-20308. doi:10.1074/jbc.M009726200

[22] Katagiri, T., Ishiyama, K., Kato, T., Tabata, S., Kobayashi, M. and Shinozaki, K. (2005) An important role of phosphatidic acid in ABA signaling during germination in Arabidopsis thaliana. Plant Journal, 43, 107-117. doi:10.1111/j.1365-313X.2005.02431.x

[23] Costa França, M.G., Matos, A.R., Darcy-Lameta, A., Passaquet, C., Lichtlé, C., Zuily-Fodil, Y. and Pham-Thi, A.T. (2008) Cloning and characterization of droughtstimulated phosphatidic acid phosphatase genes from Vigna unguiculata. Plant Physiology and Biochemistry, 46, 1093-1100. doi:10.1016/j.plaphy.2008.07.004

[24] Santos-Rosa, H., Leung, J., Grimsey, N., Peak-Chew, S. and Siniossoglou, S. (2005) The yeast lipin Smp2 couples phospholipid biosynthesis to nuclear membrane growth. EMBO Journal, 24, 1931-1941. doi:10.1038/sj.emboj.7600672

[25] Finck, B.N., Gropler, M.C., Chen, Z., Leone, T.C., Croce, M.A., Harris, T.E., Lawrence Jr., J.C. and Kelly, D.P. (2006) Lipin 1 is an inducible amplifier of the hepatic PGC- $1 \alpha /$ PPAR $\alpha$ regulatory pathway. Cell Metabolism, 4, 199-210. doi:10.1016/i.cmet.2006.08.005

[26] Han, G.S., Siniossoglou, S. and Carman, G.M. (2007) The cellular functions of the yeast lipin homolog PAH1p are dependent on its phosphatidate phosphatase activity. The Journal of Biological Chemistry, 282, 37026-37035. doi:10.1074/jbc.M705777200

[27] Yang, P., Li, X., Shipp, M.J., Shockey, J.M. and Cahoon, E.B. (2010) Mining the bitter melon (Momordica charantia I.) seed transcriptome by 454 analysis of non-normalized and normalized cDNA populations for conjugated fatty acid metabolism-related genes. BMC Plant Biology, 10, 250. doi:10.1186/1471-2229-10-250 